\title{
In situ quantification and analysis of large jellyfish using a novel video profiler
}

\author{
William M. Graham ${ }^{1,2, *}$, Daniel L. Martin ${ }^{1}$, Jonathan C. Martin ${ }^{2}$ \\ ${ }^{1}$ Dauphin Island Sea Lab, 101 Bienville Boulevard, Dauphin Island, Alabama 36528, USA \\ ${ }^{2}$ Department of Marine Sciences, University of South Alabama, Mobile, Alabama 36688, USA
}

\begin{abstract}
Ecological studies involving large jellyfish have been limited by the inability of oceanographers to measure the abundance and distribution patterns of these highly aggregated animals at local scales. Conventional plankton nets are undesirable in these applications because they cannot sample volumes large enough to accurately determine jellyfish concentration, nor do they have adequate spatial resolution to account for the ubiquitous patchiness of most large jellies. Nets are also notorious for damaging the watery bodies of jellyfish. To overcome these problems, we have developed a video system for use in the in situ study of large jellyfish. The design of our JellyCam is easily replicated since it incorporates commercially available components within a frame designed to hold hydrographic instrumentation available at most marine laboratories. We present data sets from 2 occasions as a demonstration of the utility of the JellyCam. On one occasion, a vertical profile of medusae of Pelagia noctiluca revealed intense layering of these jellyfish at the pronounced halocline/pycnocline. Most jellyfish in this layer were swimming toward the surface, and it was hypothesized that retarded forward-swimming velocity at the halocline, due to salt retention in jellyfish, caused this accumulation. A separate $800 \mathrm{~m}$ long horizontal transect of Phyllorhiza punctata medusae revealed distinct concentrated bands of jellyfish associated with increased chlorophyll concentration. Concomitant hydrographic data from the JellyCam showed that accumulation of both jellyfish and chlorophyll was associated with a hydrographic front. These data sets demonstrate that this system is capable of the desired $2 \mathrm{~m}^{3}$ resolution, which is adequate for the observation and quantification of jellyfish distributions around small-scale physical discontinuities (e.g. fronts and pycnoclines). A series of side-by-side comparisons with a conventional plankton trawl resulted in comparable measurements of large jellyfish (Aurelia aurita) concentrations. Though in situ videography by itself is a powerful tool for investigating jellyfish, its use in conjunction with conventional nets or other technologies, such as acoustics and self-propelled vehicles (e.g. remotely operated vehicles and submersibles), will provide the most comprehensive view of jellyfish distribution in 3 dimensions.
\end{abstract}

KEY WORDS: JellyCam $\cdot$ Scyphomedusae $\cdot$ Gelatinous zooplankton $\cdot$ Behavior $\cdot$ Fronts $\cdot$ Pycnoclines

\section{INTRODUCTION}

The potential importance of large jellyfish $(>2 \mathrm{~cm})$, including the scyphomedusae, as consumers and transformers of energy and nutrients in the marine ecosystems has been widely demonstrated using both laboratory and field-derived measurements of feeding, metabolism, growth and reproduction (e.g. Purcell 1992, 1997, Olesen et al. 1994, Arai 1997 and references therein, Frandsen \& Risgard 1997, Watanabe \& Ishii 2001). However, the impact of jellyfish is limited by our inability to apply such rate-process measurements to accurate quantification of jellyfish abundance, distribution and dispersion within the water column. Quantification of large jellyfish is notoriously difficult and rife with problems unique to their watery composition, large size and localized concentration (Hamner et al. 1975, Omori \& Hamner 1982). Biological oceanographers, faced with the problem of accuracy in sampling large jellyfish, have difficulty putting these animals in the correct ecological context. 


\section{Problems with conventional net sampling}

Net sampling has several factors that affect the accuracy of quantifying large jellyfish. Foremost is the problem of jellyfish patchiness. Though patchiness is a universal concern among marine zooplankton populations (Omori \& Hamner 1982, Hamner 1988, Laval et al. 1989, Davis et al. 1992, Tiselius 1998), jellyfish patchiness in the form of aggregations and swarms is especially pronounced at horizontal scales of 10 s to $1000 \mathrm{~s}$ of $\mathrm{m}$ and at vertical scales of 1 to $10 \mathrm{~s}$ of m (Graham et al. 2001). Problematically, jellyfish patchiness at these critical spatial scales corresponds to typical zooplankton tow lengths, and in turn contributes to the large variance between replicate tows. While patchiness was at one time considered an excuse to avoid jellyfish, we now realize small-scale jellyfish aggregations are quite important within coastal marine communities (Gibbons et al. 1992, Olesen 1995, Purcell et al. 2000, Graham et al. 2003).

Another dilemma of traditional net sampling is the relative rarity of large jellies. In comparison with concentrations of smaller $(<1 \mathrm{~mm})$ plankton, large jellyfish are always numerically rare, perhaps by several orders of magnitude. For statistical use, measured zooplankton quantities must be large enough to ensure both precision and accuracy. For smaller net plankton, oceanographers are typically satisfied with sub-sample counts of 100 individuals, which translates into a precision of $\pm 20 \%$, and as a general 'rule of thumb' a doubling of sampling precision requires a 4 -fold increase in counting effort (Postel et al. 2000). While obtaining a minimum of 100 specimens $<1 \mathrm{~mm}$ in length is not difficult with a plankton net, a tow yielding a minimum of 100 large jellyfish is certainly not practical. To overcome this drawback, several recent studies have utilized large opening mid-water or otter trawls to study jellyfish distributions (Pogodin 1998, Brodeur et al. 1999, Graham 2001). Large trawls, however, are cumbersome and require a substantial increase in effort and cost to operate. In addition large trawls are more difficult to quantify because of the tendency for the trawl mouth area to fluctuate under variable hydrodynamic pressure. Trawls with wide mesh tend to select only larger individuals and will inflict substantial physical damage to gelatinous organisms.

\section{Recent technological advances in zooplankton ecology}

A variety of advances including in situ acoustical and optical methodologies have recently emerged in zooplankton ecology (reviewed by Schulze et al. 1992, Smith et al. 1992, and Sprules et al. 1992). Since large gelatinous zooplankton have resolvable acoustical properties (Monger et al. 1998, Brierley et al. 2001, Warren et al. 2001), acoustical approaches can provide very good information about the distribution of jellyfish biomass in concentrated aggregations (e.g. Purcell et al. 2000). However, acoustics neither provide information on taxonomy nor on behavior, as can be acquired using an optical approach. Also, acoustically derived biomass estimates must always be groundtruthed, which resurrects the underlying problems of nets. While we believe that the most complete quantification of jellyfish abundance and distribution will undoubtedly require combined use of nets, acoustics and optics (Sameoto at al. 1993, Skjoldal et al. 2000), little effort has been made to develop an applicable optical system for the study of large jellyfish.

Several optical systems developed and refined over the past 2 decades are used as a technical starting point for designing a system to meet our particular needs. These systems, characterized as either optical plankton counters (OPCs) or direct-imaging systems (e.g. cameras and scanners) have greatly increased the understanding of plankton distributions across scales relevant to individual organisms. While this is highly desirable with respect to large jellyfish, there are key limitations to these technologies. The OPC technologies emerged with great promise of rapid quantification of plankton size-classes over the entire water column without the laborious task of manually sorting and counting numerous net samples (Herman 1988). However, the current-generation OPCs and the recently introduced Laser OPCs (LOPC) have an upper size-limit of ca. $2 \mathrm{~cm}$ (Herman 1992), and they do not provide adequate taxonomic information and differentiation from non-living particles (Herman 1992, Halliday et al. 2001, but see Grant et al. 2000, Zhang et al. 2000). Also the small tunnel opening of the OPC is not conducive to sampling large jellyfish. Thus, OPC technology is not considered appropriate for large jellyfish.

Direct-imaging technologies offer the best conceptual starting point for the in situ quantification of large jellyfish. While a number of in situ zooplankton imaging systems have been developed, these can be grouped as those that image undisturbed animals and those that concentrate animals. Among the latter are the Silhouette Camera (Ortner et al. 1979, 1981, Olney \& Houde 1993) and the Icthyoplankton Recorder (Lenz et al. 1995), both of which utilize a plankton net to concentrate the sample prior to imaging. While this approach allows the user to sample a larger volume of water, it is best suited for smaller 'net' plankton, but not the large jellyfish (i.e. medusae) that we target. Also, sample concentration does not alleviate fundamental error associated with plankton net sampling due to net avoidance, sample volume calculation and damage or destruction of very fragile organisms. How- 
ever, Kasuya et al. (2001) recently designed and implemented a variation on the Ichthyoplankton Recorder for quantifying the distribution and abundance of the lobate ctenophore Bolinopsis mikado Moser in Tokyo Bay, Japan, which illustrates that some groups of jellies may be suitable for this approach.

A second approach, clearly more suitable for imaging of large jellyfish, are systems that image individual plankton without necessarily disturbing the sensible flow-fields around the animals. In this category we include SCUBA diving, manned submersibles, remotely operated or autonomous underwater vehicles (ROVs and AUVs), and video plankton recorders (VPRs). Among these, SCUBA is the most readily available approach for in situ zooplankton investigation. Hamner et al. (1975) provide a thorough overview of the utility of SCUBA in the study of gelatinous animals, and numerous studies have subsequently applied water-column SCUBA to understand jellyfish distribution and behavior (e.g. Madin 1988, Hamner et al. 1994, Costello et al. 1998). SCUBA allows the observer to handle, collect, manipulate and closely photograph or otherwise describe the undisturbed jellies in detail. While upper water-column SCUBA in the open sea requires specialized training for 'blue-water' diving (Hamner et al. 1975, Coale et al. 1986, Madin 1988), supplemental equipment is not prohibitively expensive for most scientific programs. The obvious drawbacks of SCUBA are limitations in duration, spatial coverage and attainable depth (but see Orzech 1984).

Earliest in situ research on marine zooplankton in the open sea used manned submersibles (Bernard 1955, Trégouboff 1956). Yet it was not until the early 1980s that submersibles were systematically used for the study of mid-water jellyfish and their vertical distribution (Mackie \& Mills 1983, Youngbluth 1985). Manned submersibles have been used to make behavioral observations (Harbison 1992) and to conduct in situ physiological experiments (Youngbluth et al. 1988, Bailey et al. 1995) on organisms that otherwise would have been out of reach of human inquiry. However, the constraint of power consumption typically means that submersibles can make only a few dives over a $24 \mathrm{~h}$ period. Moreover, the extraordinary cost of operating manned submersibles precludes all but a few oceanographers from using them in systematic studies of mid-water organisms.

More recently, advances in robotics technology and data telemetry have produced a new era of undersea study using tethered ROVs and untethered AUVs. While AUV technology is still in its infancy, ROVs have gained enormous popularity in the study of deep benthic and mid-water organisms because they overcome the limitations of submersibles: lower relative cost, increased dive duration and faster operational turn- around time (Schulze et al. 1995). ROVs have been used not only to describe new species of mid-water gelatinous animals (e.g. Harbison et al. 2001), but to systematically quantify jellyfish distribution and abundance. Recently, ROVs have been used to measure inter-annual variability (Raskoff 2001), seasonal variability (Silguero \& Robison 2000), and metabolic rates (Youngbluth \& Båmstedt 2001) of mid-water gelatinous animals. Still, the operational cost of using deep-diving ROVs has restricted their use to only a handful of research programs around the world. Also, the larger ROVs (such as those used in the examples above) are typically dedicated to a specific surface support vessel, which both increases operational cost and limits portability. Smaller, less expensive ROVs are not well-suited to systematic distributional studies because they typically lack both the required propulsion and navigational tools needed to run along set transects.

VPRs are a class of instruments based on a sampling strategy previously occupied solely by the continuous plankton recorder (CPR; Hardy 1926, Warner \& Hays 1994). The first generation of VPR was developed at Woods Hole Oceanographic Institute (WHOI; see Davis et al. 1992 and 1996 for design details) for use in ecological studies of the George's Bank (e.g. Benfield et al. 1996, Gallager et al. 1996, Ashjian et al. 2001). The WHOI VPR design incorporated 4 video cameras, each of different magnification, that imaged the same illuminated parcel of water. Key to this approach was a fixed illumination field of known volume that was used to reconstruct the very high-resolution plankton dispersion pattern. Unlike the CPR, the VPR provides additional information on individual plankton behavior such as swimming orientation and feeding posture (Benfield et al. 2000). Because the VPR is a towed instrument, there is no requirement for on-board propulsion, and the video signal and all concomitant water column measurements (e.g. depth, temperature, salinity, fluorescence, etc.) are transmitted via the tow cable in real-time to the shipboard operator. Since the WHOI instrument was developed for open-ocean investigation, the cost of replication of the instrument will likely prohibit its widespread use among the oceanographic community. However, at least 1 lowcost alternative to the WHOI VPR design has emerged (Tiselius 1998). Should a cost-efficient industry standard emerge, the VPR will likely gain in popularity since it is relatively portable and can be deployed and recovered with standard oceanographic deck equipment. Moreover, this technique provides enormously valuable biological and physical data over a virtually unlimited range of sampling scales. In developing an imaging system for large jellyfish, we adopted the towed VPR strategy, but we made specific modifications to maximize its utility for our target animals. 
Here we present details of our JellyCam, an in situ video camera system specifically designed for the study of large jellyfish. This particular system, however, is only 1 possible configuration; others may find specific components unnecessary or of low priority, and opt to eliminate these components. In the broader sense, this paper presents a strategy for the design of a similar system. Unlike other current-use technologies, such as the VPR described by Davis et al. (1992), our design minimizes engineering steps and uses off-theshelf components whenever possible. By following this strategy, a similar design can be replicated for several 1000 US dollars in its most basic configuration of camera, light source and frame. In addition, our package allows for the incorporation of commonly used hydrographic instrumentation available at most marine research facilities. Most importantly, choices in our design were guided by specific research questions, rather than vice versa. Our priority needs were: (1) large sampling volume (large area and long tow time); (2) quantifiable for animal density and spacing, with at least $2 \mathrm{~m}$ vertical and $1 \mathrm{~m}$ horizontal resolution; (3) real-time hydrographic measurements incorporating accurate geographic position; (4) taxonomic recognition of target jellyfish; and (5) portability and costeffectiveness. We present 2 data sets, collected during recent years, which demonstrate the utility of this camera system. Finally, we present a side-by-side comparison of this camera system with conventional plankton trawls to assess the utility and limitations of our system.

\section{MATERIALS AND METHODS}

Frame design. The JellyCam frame (Fig. 1a) was constructed of $9 \mathrm{~mm}$ thick stainless steel rod. The dimensions of the frame were $1.73 \mathrm{~m}$ (length) $\times 0.56 \mathrm{~m}$ (width) $\times 0.29 \mathrm{~m}$ (height). Four runners constructed of stainless steel right-angle bar were welded to form an interior cage $0.97 \mathrm{~m}(\mathrm{l}) \times 0.30 \mathrm{~m}(\mathrm{w}) \times 0.28 \mathrm{~m}(\mathrm{~h})$. These dimensions allowed a commercially available conductivity-temperature-depth probe (CTD) frame (SeaBird) to fit securely within this internal frame (Fig. 1b). To keep the frame body oriented into the direction of the ship, stainless steel stabilizing vanes (Fig. 1c) were attached at the rear of the frame. A 4-point bridle constructed of stainless steel wire and shackles (Fig. 1d) was connected to the conducting hydro-wire by a swivel.

Light source and collimation. A sealed $250 \mathrm{~W}$ halogen light source (Model UWL-250; Outland Technologies) placed at the front of the frame produced a beam of light of approximately 4000 lumen in a direction $90^{\circ}$ to the long axis of the frame, and thus normal to relative water flow past the frame (Fig. 1e). We followed the general strategy of Lee \& Hall (1989) to produce a $10 \mathrm{~cm}$ thick light slab; the beam was first collimated using a positive focal length Fresnel lens (Item 15; Fresnel Technologies) with an in-water focal length of $30 \mathrm{~cm}$ (i.e. halogen light source was $30 \mathrm{~cm}$ from the collimating lens). The $10 \mathrm{~cm}$ collimated light was then fanned in the vertical axis by using a $70^{\circ}$ lenticular array (Item 260; Fresnel Technologies) (Fig. 1f).

Video image. A CCD color video camera head enclosed in a stainless steel underwater housing (Model UWC-400; Outland Technologies) was mounted on the outboard side (rear left in this application) of the frame and looked through the $10 \mathrm{~cm}$ light slab (Fig. 1g). The CCD chip $(1.3 \mathrm{~cm})$ used in this application had 0.3 lux light sensitivity and 570 horizontal lines of resolution (Item WDCC6300S/P; Weldex). The lens was $4.3 \mathrm{~mm}$ at f2.0. Final dimensions of each digital frame were 768 (horizontal) by 494 (vertical) pixels. The view of the video was obliquely offset by $30^{\circ}$ to the left such that final in-water video signal showed the left-most edge of the frame (Fig. 1h).

The dimensions of the imaged area were empirically determined in a large seawater tank at Dauphin Island Sea Lab. We used polyvinyl chloride (PVC) tubes fixed normally to the frame in the plane of the light field (i.e. outboard and vertical dimensions) to mark and measure the horizontal outboard distance and the vertical distance at both the inboard and the outboard edges of the field of view. Distance between video camera and the projected light path was $1.0 \mathrm{~m}$ on the inboard side and $1.7 \mathrm{~m}$ on the outboard side of the video image, and the $10 \mathrm{~cm}$ thick light slab was completely within the focal depth of field of the camera. The intersection of the light path with the camera view resulted in a trapezoidal illumination field that was $0.71 \mathrm{~m}$ high and $1.21 \mathrm{~m}$ high on the inboard and outboard edges of the field, respectively, and the width of the illumination field was $1.38 \mathrm{~m}$ (Fig. 1i). The area of the illuminated field was $1.67 \mathrm{~m}^{2}$. The side-lighted imaging was necessary to reduce suspended-particle backscatter and to enumerate jellies as they pass through the light slab.

The video signal (NTSC format) and 110 VAC power were transmitted through the same umbilicus, which was manually handled during deployments. The camera was lowered and raised using a small, portable electric winch. A conducting hydro-wire transmitted real-time data from the CTD package (SBE 25 with Wetstar fluorometer; Model 9602012, Wetlabs) to the processor and video deck unit (Model CON-3000; Outland Technologies) on the ship (Fig. 1j). All CTD data were also stored internally and uploaded after each cast. To facilitate cable handling, loops of nylon rope fixed to the video/power cable at $5 \mathrm{~m}$ intervals served as attachment points to the hydro-wire. The nylon loops were secured with wire ties. Selected real-time 
(d) bridle attachments
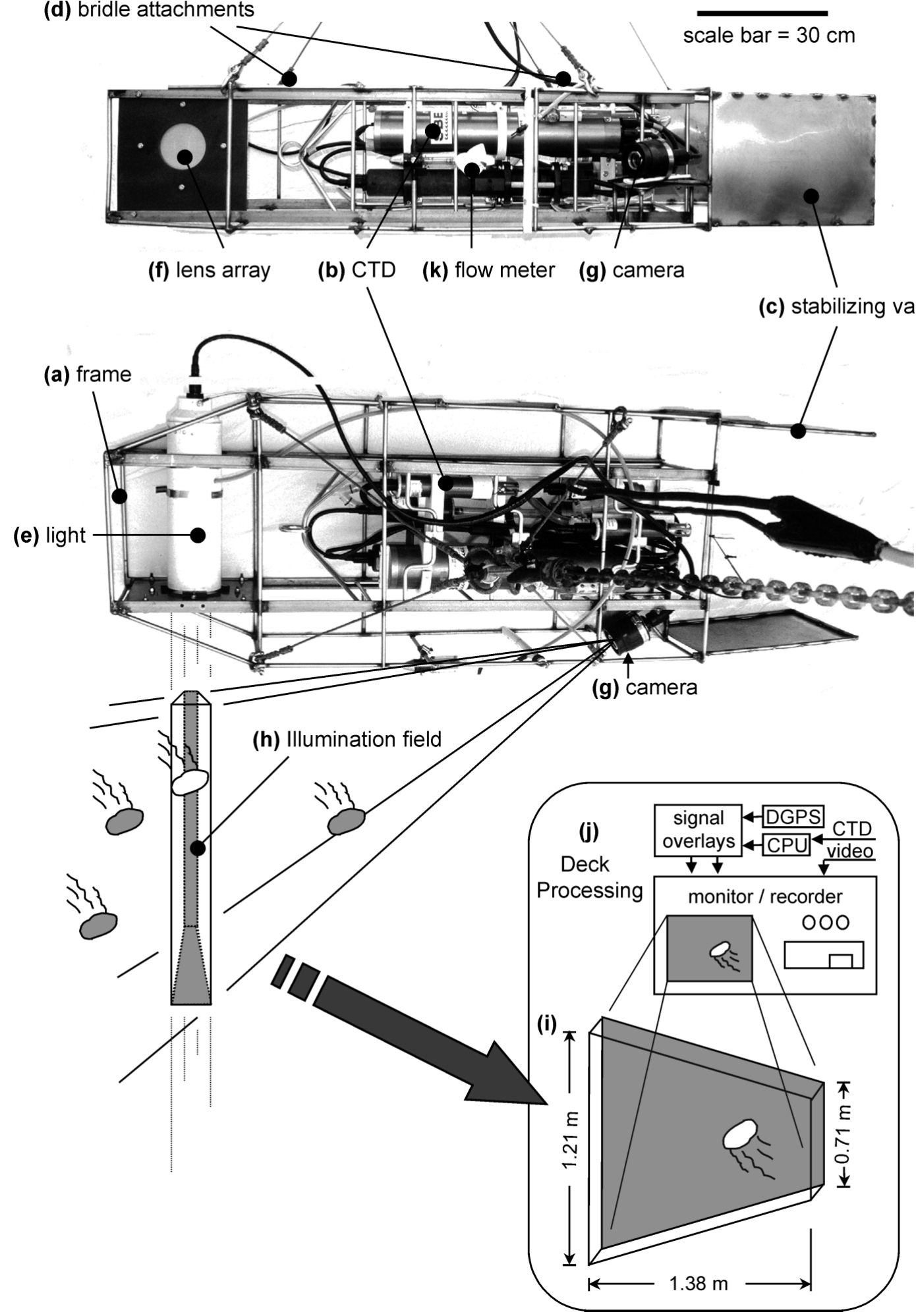

Fig. 1. Diagrams of the JellyCam system showing both side (upper) and top (lower) views of the frame and instrumentation (a-g). The illumination field $(\mathrm{h})$ and hypothetical jellyfish targets are shown in the top-view diagram. This illumination field has been rotated in the inset diagram (i) to illustrate the dimensions of the illuminated area. Processing and recording of video, conductivitytemperature-depth (CTD) and GPS data is also shown in the inset (j). The direction of movement through the water is from right to left 
CTD data (sequential scan number, depth, temperature and salinity) and differentially corrected Global Positioning System (DGPS; Garmin GPS III+ and differential beacon receiver) data were overlaid on the real-time video output (Model 5000A; Outland Technologies) and recorded to digital tape media (MiniDV; Sony). The refresh rate of the CTD and DGPS data on the video overlay was 1 and $0.5 \mathrm{~s}^{-1}$, respectively. Hi-8 format analog video was also recorded to serve as back-up and to prevent loss of data during digital tape changes.

Comments on deployment. Horizontal and vertical sampling resolution of the JellyCam was dictated by a number of instrumental, handling and environmental factors. Our desire was to have at least $1 \mathrm{~m}$ horizontal resolution and $2 \mathrm{~m}$ vertical resolution. The CTD package had a real-time refresh rate of $1 \mathrm{~s}^{-1}$, therefore a $1 \mathrm{~m}$ $\mathrm{s}^{-1}$ tow speed (relative to water) allowed the $1 \mathrm{~m}$ horizontal resolution we desired. Since the GPS system provides only 'speed over ground', we placed a flow meter (Model 2030R; General Oceanics) on the camera frame within the video camera field-of-view (Fig. 1k) and instructed the ship's helm to alter speed according to variations in the meter's rotor speed. By counting rotor revolutions of the calibrated flow meter, one could also obtain finer resolution of horizontal distance between individual animals if such information was desired (data not shown here). Vertical resolution was limited by the largest dimension of the imaged area (1.21 $\mathrm{m}$ on the outboard edge); however, surface swell usually moved the camera over a range of about $2 \mathrm{~m}$. Under calm sea states (typical in the northern gulf of Mexico during summer), we stepped the JellyCam vertically in $2 \mathrm{~m}$ increments in the surface layer at and above the pycnocline. Below the pycnocline, steps were usually increased to $4 \mathrm{~m}$ increments. Since most large jellyfish in the northern Gulf of Mexico occur close to shore in relatively shallow water, we typically did not exceed $50 \mathrm{~m}$ with the JellyCam. However, under calm seas and light wind, we have on occasion exceeded $80 \mathrm{~m}$ with little difficulty in handling the umbilicus.

Field deployment, analysis and validation. To demonstrate our system's utility for constructing vertical profiles of jellyfish, we deployed the JellyCam from the $32 \mathrm{~m}$ RV 'Pelican' in the northern Gulf of Mexico on 12 August 1999 during a bloom of the oceanic jellyfish Pelagia noctiluca Forsskal. This exercise was conducted approximately $130 \mathrm{~km}$ south of Choctawhatchee Bay (Florida) in clear, oceanic waters under high ambient light conditions at 1100 (CST). The camera was lowered to $18 \mathrm{~m}$ in $2 \mathrm{~m}$ increments and then from 18 to $38 \mathrm{~m}$ in $4 \mathrm{~m}$ increments. At each stop the camera was horizontally towed at $1 \mathrm{~m} \mathrm{~s}^{-1}$ for $1 \mathrm{~min}$. In addition to the video and CTD data collected using the
JellyCam, upper water column current velocities were measured using a $1200 \mathrm{kHz}$ narrowband acoustic doppler current profiler (ADCP, RD Instruments) mounted on the hull of the ship. Current velocity was recorded in $2 \mathrm{~m}$ depth bins between 4 and $24 \mathrm{~m}$; averages and standard deviations of current velocity for each bin were calculated from 10 sequential pingensembles over a 1 min interval during the JellyCam cast. To demonstrate the utility of the system for measuring horizontal dispersion of jellyfish, we conducted a long transect in the turbid waters of coastal Louisiana on 12 August 2000 at 12:00 h (CST). In this case, the Jellycam was lowered to $0.75 \mathrm{~m}$ below the surface and towed at approximately $1 \mathrm{~m} \mathrm{~s}^{-1}$ for $25 \mathrm{~min}$ across a dense aggregation of the large jellyfish Phyllorhiza punctata von Lendenfeld.

Validation by ground-truthing is important when introducing a new methodology such as our JellyCam. On 16 and 17 September 2001, we made 7 comparative net-video tows through aggregations of Aurelia aurita Linne in the northern Gulf of Mexico. These comparisons were made under varying ambient lighting: 4 during daytime $(14: 00$ to $16: 00 \mathrm{~h} \mathrm{CST}), 1$ at dusk (16:00 to $16: 30 \mathrm{~h} \mathrm{CST}$ ), and 2 at night (20:00 to $22: 00 \mathrm{~h}$ CST). These 7 tows were made by simultaneously deploying the JellyCam and a $1 \mathrm{~m}^{2}$ opening-closing Tucker trawl (1 mm mesh) on the port and starboard sides of the ship, respectively. The camera and net were both centered on $2 \mathrm{~m}$ depth during sampling. Upon recovery of the trawl, all $A$. aurita were immediately sorted and counted. By coordinating the 2 deployments, we identified that portion of video taken while the Tucker trawl was actually open and sampling. Only this portion of video was reviewed in the lab. To reduce sampling problems associated with aggregated dispersion of jellies, we intentionally targeted discrete aggregations of jellyfish in this exercise. Yet to avoid overwhelming the Tucker trawl net, transects were terminated when real-time video viewing estimated $30 \mathrm{~A}$. aurita. All tows were between 10 and $30 \mathrm{~min}$ in duration. Actual video counts of $A$. aurita were made in the laboratory. To avoid bias, the number of $A$. aurita recovered from the Tucker trawl was withheld from the video technician.

All recorded digital video was reviewed at the Dauphin Island Sea Lab using a high-resolution monitor in a darkened room. All gelatinous animals were enumerated and identified to the lowest possible taxonomic level. The system described here was limited in its utility to accurately identify some gelatinous animals. Identification to species was possible for larger scyphomedusae, but smaller transparent animals (e.g. ctenophores, salps and hydromedusae), especially under high ambient light, required either validation by a qualitative net tow or identification to a coarser taxo- 
nomic level. We used the digital video playback in either 'slow' or 'frame-by-frame' mode to increase the certainty of identifications. Still, it was prudent to score each identification using a 'certainty index' value of 1 to 5 , where 1 was the highest degree of certainty of identification. The data analyses presented here used certainty values of at least 3 .

Volumetric densities of jellyfish were calculated by counting flow meter revolutions during the first $10 \mathrm{~s}$ of each 1 min depth interval or during the full horizontal transect. The calibrated flow meter counts were used to calculate the distance traveled for each transect, which was then multiplied by the image area to obtain volume sampled over the entire transect. In addition to identification, radial orientation of animals in the plane of the image was recorded. We assigned 5 categories of orientation in the direction of animal swimming (i.e. aboral surface forward for medusae and tentaculate ctenophores, oral end forward for lobate ctenophores). These categories were as follows: straight up, straight down, angled up, angled down, horizontal.

\section{RESULTS AND DISCUSSION}

Traditional sampling devices for smaller zooplankton $(<2 \mathrm{~cm})$ such as bottles, nets, pumps and traps will not adequately sample the heterogeneous distribution of larger jellyfish and other patchily dispersed micronekton (Cassie 1963, Hamner et al. 1975, Sameoto et al. 2000). While larger nets such as the Isaacs-Kidd midwater trawls, Tucker trawls and otter trawls have been used for large jellyfish sampling (e.g. Pages et al. 1996, Brodeur et al. 1999, Graham 2001), large nets are cumbersome, require large vessels, and still do not provide individual-scale information. Our in situ video system overcomes the primary faults of net sampling for large jellyfish by allowing us to sample large volumes of water without disturbing the behavior and position of large gelatinous zooplankton. The key features of our system design are the large viewing area $\left(1.67 \mathrm{~m}^{2}\right)$, collimated light slab, integrated hydrographic data, and real-time viewing of both video and hydrographic data. By incorporating DGPS data, we are able to measure with precision the horizontal as well as vertical dispersion of large jellyfish around physical discontinuities (e.g. fronts and pycnoclines). Real-time viewing of video also provides shipboard scientists with a tool to rapidly survey the abundance and composition of jellies at a particular location before conducting additional targeted sampling. Targeted sampling may include additional net sampling or SCUBA diving to collect animals or tissue samples. Advanced knowledge of depth, abundance and taxonomic information is valuable for reducing time and effort at collection sites. In particular we have found it useful to know, prior to SCUBA diving, the abundance and distribution of painful species at a particular locale.

\section{Field examples}

The vertical profiles of Pelagia noctiluca, as well as concomitant water column structure, collected in August 1999 are an excellent demonstration of our camera system's resolution. On this particular day, the upper $40 \mathrm{~m}$ of the water column was thermally stratified with an indication of steeper thermal gradients below ca. $25 \mathrm{~m}$ (Fig. 2a). A pronounced halocline between 11 and $20 \mathrm{~m}$ corresponded to the location of the pycnocline (Fig. 2a,b). As is typical for surface waters of the northern Gulf of Mexico during summer, upper water column density structure is dependent on salinity rather than temperature. Winds were calm on this day and the water layer above $11 \mathrm{~m}$, while suggesting a history of mixing, was stratified as evidenced by the slight tilt of the density profile in Fig. $2 \mathrm{~b}$. The ADCP-derived current velocity profile over the upper $25 \mathrm{~m}$ revealed a region of intense current shear within the pycnocline. This shear layer was seen as an increase of approximately $30 \mathrm{~cm} \mathrm{~s}^{-1}$ in current velocity between 10 and $14 \mathrm{~m}$ in Fig. $2 \mathrm{~b}$.

Medusae of Pelagia noctiluca occurred only between 10 and $30 \mathrm{~m}$ during this cast. Most interestingly, however, was our measurement of a 10-fold increase in jellyfish concentration over the $2 \mathrm{~m}$ increment between 14 and $12 \mathrm{~m}$, followed by a 100-fold decrease between 12 and $10 \mathrm{~m}$. The spatial relationship between $P$. noctiluca distribution and water column structure and current shear is striking (Fig. 2c). The peak in medusa concentration at $12 \mathrm{~m}$ was exactly coincident with the upper surface of the halocline/pycnocline and with the layer of maximum current shear. A major criticism of traditional net sampling is the inadequate resolution of these types of variations when compared to the highresolution capability of video systems (Schulze et al. 1992). At best, the resolving scale of conventional nets is about $5 \mathrm{~m}$ in the vertical dimension (Sameoto et al. 2000), and the vertical heterogeneity of $P$. noctiluca seen in Fig. 2c would certainly have been lost with even the most careful net sampling.

Despite the close relationship between the vertical distribution of Pelagia noctiluca and the physical structure of the water column, it is difficult to infer a mechanistic explanation for this patterning from static distributional data. Making behavioral inferences from in situ video requires an assumption that the instrument package does not alter the behavior of the target animals. Hydrodynamic disturbance created by the camera frame is minimal, since the viewing area is set off 

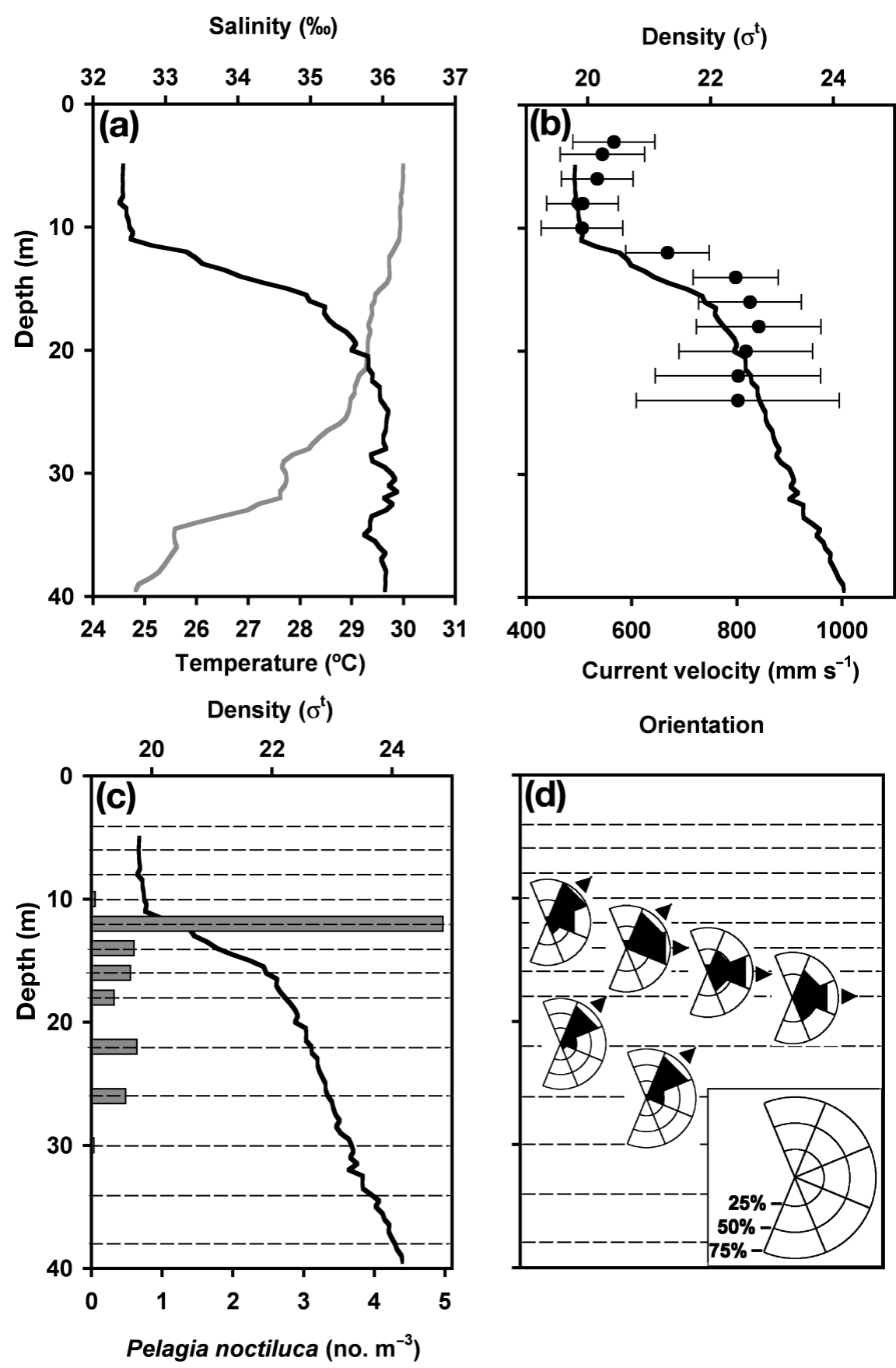

Fig. 2. Pelagia noctiluca. (a) Vertical profiles of temperature and salinity. (b) Vertical profiles of seawater density and acoustic doppler current profiler (ADCP)-measured current shear (mean $\pm \mathrm{SD}$ of 10 sequential ping-ensembles). (c) Vertical distribution of jellyfish with density structure. (d) Circular frequency histograms of vertical swimming orientation; triangles indicate modes of orientation in the 5 categories. Circular frequency scale is explained in the inset

to the side of the frame's front end (Fig. 1). The second consideration is the light source, since many zooplankters, including jellyfish, are sensitive to 'white' light (Forward 1988). Other video systems targeting smaller zooplankton $(<2 \mathrm{~cm})$ have overcome light effects by using strobes (Davis et al. 1992, Tiselius 1998) or red light (Gallagher et al. 1996). While many large jellyfish are sensitive to light (Hamner 1995, Schuyler \& Sullivan 1997), reaction times to stimuli are much longer than the brief $(<1 \quad s)$ exposure of jellyfish to the collimated light beam. Therefore, we believe the orientation data collected using the JellyCam system accurately reflected undisturbed orientation of the jellyfish.

Information about jellyfish behavior is often crucial to understanding the dynamics of jellyfish aggregations (Hamner 1995, Purcell et al. 2000, Graham et al. 2001). We were able to glean information on Pelagia noctiluca swimming behavior from our video profiles. As seen in the vertical sequence of orientation histograms in Fig. 2d, the mode of $P$. noctiluca swimming was at an upward angle as they approached the strong pycnocline. Within the 14 to $18 \mathrm{~m}$ layer, a marked deflection of swimming modes toward the horizontal plane was possibly due to the medusae entering the region of high current shear. Above this, however, an upward mode of swimming was regained (Fig. 2d). With the exception of the 14 to $18 \mathrm{~m}$ layer, the tendency of upward swimming was presumably due to a daily vertical migration that we had previously observed (unpubl. data). Accumulation of $P$. noctiluca at $12 \mathrm{~m}$ can be explained by behavior (upward swimming) interacting with the steep halocline. Because medusae osmotically conform to seawater salt content, $P$. noctiluca originating from below the halocline would have been higher in salt content and denser than the overlying surface layer. This would retard forward velocity, but not orientation, of $P$. noctiluca as they approached $12 \mathrm{~m}$, resulting in their accumulation along this surface.

Results of the $800 \mathrm{~m}$ long transect across a dense aggregation of Phyllorhiza punctata medusae are presented in Fig. 3. This particular aggregation occurred in very shallow coastal waters of Lake Borgne, Louisiana, 


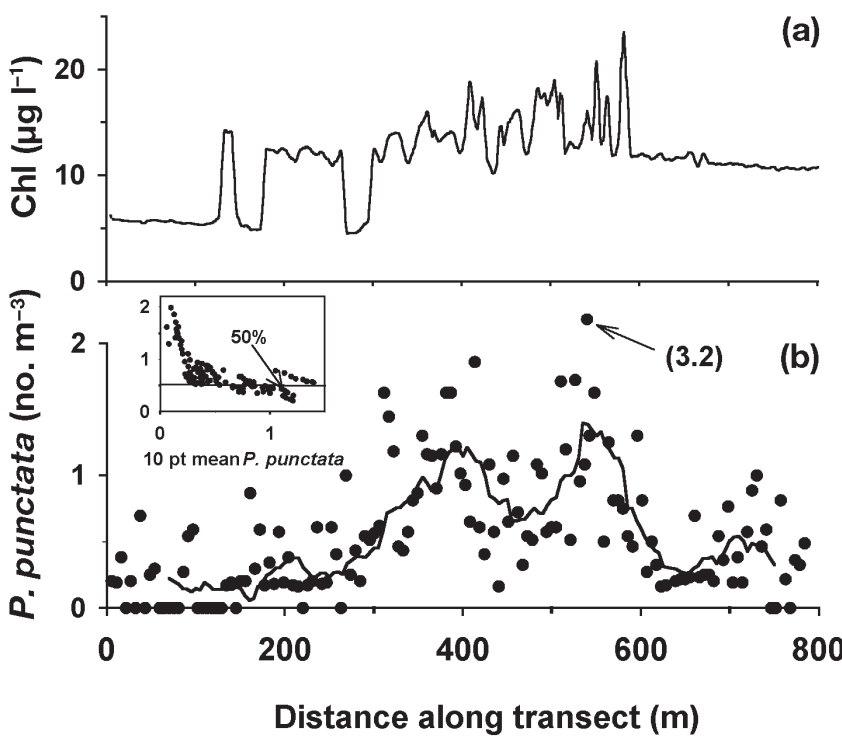

Fig. 3. Phyllorhiza punctata. (a) Concentration of chlorophyll pigment as measured by in situ fluorometry along the $800 \mathrm{~m}$ transect. (b) Horizontal dispersion of $10 \mathrm{~m}$ binned jellyfish concentrations $(\bullet)$ and the 10-point running mean (thin line). The inset presents the coefficients of variation $(\mathrm{CV}=$ mean/standard deviation) as a function of their corresponding 10 -point running means. CV is ca. $50 \%$ at higher mean jellyfish concentrations

on 12 August 2000. Water depth was only 3 to $4 \mathrm{~m}$ along the entire transect, and several vertically stratified casts showed that $P$. punctata were located only in the upper half of this water column (data not presented). Therefore, the long surface transect presents an accurate depiction of horizontal variations in concentration across the aggregation. A 10-point running mean is superimposed on the raw signal (filled circles) of medusae concentration (Fig. 3). Within the larger aggregation there were 2 distinct bands of highly concentrated medusae, each $\sim 100 \mathrm{~m}$ wide. Qualitatively, highest P. punctata concentrations were coincident with elevated chlorophyll concentration (solid line in Fig. 3). One explanation for this relationship is the release of phytoplankton from zooplankton grazing pressure. Assuming concentrations of about 1 medusa $\mathrm{m}^{-3}$ (Fig. 3), volumetric clearance rates on copepods of $0.8 \mathrm{~m}^{3} \mathrm{~d}^{-1}$ (Graham et al. 2003) would be sufficient to reduce copepod standing stock in these aggregations. In Chesapeake Bay, Feigenbaum \& Kelly (1984) observed a similar, albeit temporal, release from grazing predation due to the presence of the ctenophore Mnemiopsis leidyi. An alternate explanation for the patterns in Fig. 3 is that both elevated jellyfish and phytoplankton concentrations accumulated in a region of convergent flow (i.e. a front). Fig. 4 presents individual jellyfish observations of Fig. 3 with their respective temperature-salinity (T-S) characteristic, which in turn is plotted over the T-S field of the entire transect. The peak jellyfish concentrations in Fig. 3 fall within a narrow T-S envelope at the transition between 2 distinct parcels of water (T-S points circled in Fig. 4), indicating accumulation along a frontal boundary. Frontal boundaries are commonly associated with jellyfish aggregations (e.g. Graham 1994, Wright \& Purcell 1997; and reviewed in Graham et al. 2001); however, the interactions between physics of the water and behavior of the animals are often obscure (Graham et al. 2001). Certainly without simultaneous hydrographic and jellyfish data, it would not have been possible to interpret aggregation patterns seen in Fig. 3.

\section{Comparison with nets}

On the whole, video-derived jellyfish concentrations were comparable to concentrations directly measured from simultaneous trawls (Fig. 5), although individual comparisons differed by as much as $40 \%$. Since the tendency for greatest deviation between sampling methods occurred at highest jellyfish concentration (Fig. 5), we expect that the horizontal distance between sampling gear from one side of the ship to the other (about $10 \mathrm{~m}$ ) was enough separation to account for the variance (i.e. local patchiness at 1 to $10 \mathrm{~m}$ scale associated with highly concentrated aggregations). (Note that coefficient of variation over 10-point running means [=10 $\mathrm{m}$ horizontal

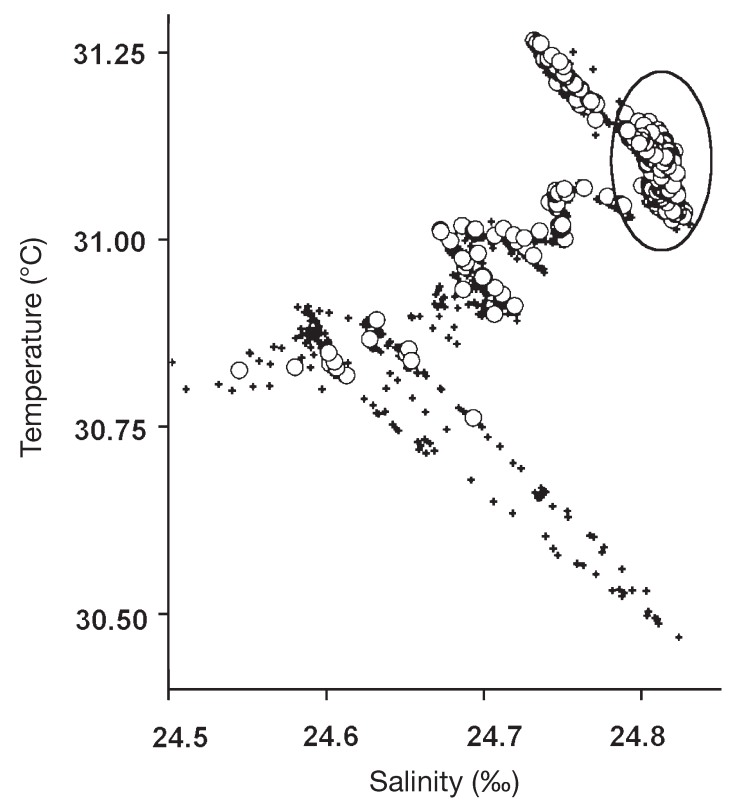

Fig. 4. Phyllorhiza punctata. Characteristic temperaturesalinity values of all jellyfish observations from the transect presented in Fig. 3. (O) temperature-salinity (T-S) values where jellyfish were observed; + : T-S values where jellyfish were not observed. The circled points are the T-S envelope of jellyfish from the 2 peaks of concentration in Fig. 3 


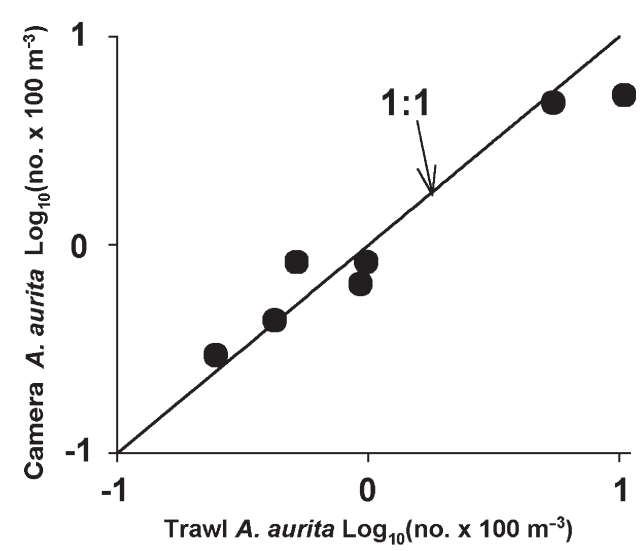

Fig. 5. Aurelia aurita. Side-by-side comparison of jellyfish concentrations measured by video and trawl. Solid line is unity between video and trawl. All data were $\log _{10}$-transformed

distance] tended to be ca. $50 \%$ for the Phyllorhiza punctata transects [see inset in Fig. 3].) The side-by-side comparison between JellyCam and Tucker trawl used only medusae of Aurelia aurita larger than $15 \mathrm{~cm}$ in diameter (no animals smaller than $15 \mathrm{~cm}$ were recovered from the net), therefore the basis for validation should be limited to only animals of this size and larger. There were no systematic deviations among the 7 comparisons that were consistent with changes in ambient light levels. While large jellyfish like A. aurita are easily quantifiable, our experience has been that smaller, transparent organisms like ctenophores are more difficult to quantify under high ambient light.

An in situ approach to study gelatinous zooplankton is not particularly novel. Hamner et al. (1975) provided an early summary of the approaches and problems of studying gelatinous animals. In comparison to conventional net sampling, Hamner and his colleagues provided ample argument that in situ approaches such as SCUBA were necessary to understand the complex distribution of these fragile organisms. Since the time of this seminal paper, technological advances in high-quality video have emerged in gelatinous zooplankton ecology (e.g. Costello et al. 1998), but we are no longer limited to 'SCUBA depth' to observe and quantify gelatinous animals.

Submersibles and ROVs have been widely used for the study of gelatinous animals over a much greater depth range than our camera system (reviewed by Youngbluth 1985 and by Bergstrom et al. 1992). Mills et al. (1996) conducted a series of submersible dives to describe the gelatinous fauna in the SW Mediterranean Sea. While general spatial patterns were presented in their study, the submersible in their case was best used for detailed observations on larger, fragile animals like siphonophores, ctenophores and medusae larger than about $1 \mathrm{~cm}$. Laval et al. (1989) made more quantitative use of a submersible for the study of gelatinous and non- gelatinous zooplankton vertical distributions off the coast of France. In addition to observations of very deep gelatinous animals, submersibles and ROVs have been used for in situ rate measurements (e.g. Youngbluth et al. 1988, Youngbluth \& Båmstedt 2001). ROVs provide the added benefit of increased time for study of gelatinous animals, but are typically limited to shallower depths than research submersibles (but see Steinberg et al. 1994). Brodeur (1998) used an ROV to observe the association between fish and jellyfish in the Bering Sea, and Purcell et al. (2000) recently used an ROV to study jellyfish aggregations and individual behavior in Prince William Sound, Alaska.

Studies like Mills et al. (1996), Brodeur (1998) and Purcell et al. (2000) serve as excellent examples of how propelled submersibles and ROVs are much better suited than our system for studying individual behavior and group interactions. Towed systems like ours are arguably better suited for the study of broad-scale distribution patterns of jellyfish than ROVs and submersibles that require careful maneuvering by the tending ship in order to traverse long horizontal distances. Our JellyCam system has the added benefit of portability, which is typically lacking in self-propelled vehicles. The few studies using ROVs or submersibles to quantify vertical distribution of gelatinous animals report resolutions on the order of 10s of m (e.g. Mackie \& Mills 1983, Laval et al. 1989). Our system, though limited by depth, has a resolution of $2 \mathrm{~m}$ vertical by $1 \mathrm{~m}$ horizontal, which is appropriately matched to the scale of individual animals in aggregations.

In summary, overall size and portability, availability of ancillary hydrographic data, and total system cost were all factored into the design of our camera system. However, the critical emerging questions in jellyfish ecology dictated that the kind of data we desired should include spatial information on individual medusae at a minimum resolution of $2 \mathrm{~m}^{3}$. The system we have described here achieves the desired resolution in a package that is functional in water depths up to at least $80 \mathrm{~m}$, is portable on medium-sized vessels, and is modular for flexibility under different circumstances. The latter feature allows for field instrumentation that is common at most marine laboratories. At present, we have logged well over $300 \mathrm{~h}$ of video in the Gulf of Mexico, and Pacific and Atlantic Oceans as part of a variety of studies that require knowledge of dispersion of individual jellyfish. The system described here will hopefully be adopted as a standard methodology for in situ quantification of large jellyfish in other marine ecological applications.

Acknowledgements. We wish to thank K. Kirsch, A. Gunter, Y. Hintz and M. Dardeau for their technical and field assistance. We also wish to thank the captain and crew of the RV 'Pelican' for their efforts in the field. This study was funded by the National Science Foundation grant OCE9733441. 


\section{LITERATURE CITED}

Arai MN (1997) A functional biology of Scyphozoa. Chapman \& Hall, New York

Ashjian CJ, Davis CS, Gallager SM, Alatalo P (2001) Distribution of plankton, particles, and hydrographic features across the Georges Bank described using the Video Plankton Recorder. Deep-Sea Res II 48:245-282

Bailey TG, Youngbluth MJ, Owen GP (1995) Chemical composition and metabolic rates of gelatinous zooplankton from midwater and benthic boundary layer environments off Cape Hatteras, North Carolina, USA. Mar Ecol Prog Ser 122:121-134

Benfield MC, Davis CS, Wiebe PH, Gallager SM, Lough RG, Copley NJ (1996) Video Plankton Recorder estimates of copepod, pteropod and larvacean distributions from a stratified region of Georges Bank with comparative measurements from a MOCNESS sampler. Deep-Sea Res II 43: 1925-1945

Benfield MC, Davis CS, Gallager SM (2000) Estimating the in-situ orientation of Calanus finmarchicus on Georges Bank using the Video Plankton Recorder. Plankton Biol Ecol 47:69-72

Bergstrom BI, Gustavsson A, Stromberg JO (1992) Determination of abundance of gelatinous plankton with a Remotely Operated Vehicle (ROV). Arch Hydrobiol Beih Ergeb Limnol 36:59-65

Bernard F (1955) Densité du plancton vu au large de Toulon depuis le bathyscaphe F.N.R.S. III. Bull Inst Oceanogr 1063:1-16

Brierley AS, Axelsen BE, Buecher E, Sparks CA, Boyer H, Gibbons MJ (2001) Acoustic observations of jellyfish in the Namibian Benguela. Mar Ecol Prog Ser 210:55-66

Brodeur RD (1998) In situ observations of the association between juvenile fishes and scyphomedusae in the Bering Sea. Mar Ecol Prog Ser 163:11-20

Brodeur RD, Mills CE, Overland JE, Walters GE, Schumacher JD (1999) Evidence for a substantial increase in gelatinous zooplankton in the Bering Sea, with possible links to climate change. Fish Oceanogr 8:296-306

Cassie RM (1963) Microdistribution of plankton. Oceanogr Mar Biol Annu Rev 1:223-252

Coale K, Michaels A, Pinto R (1986) Blue water diving equipment and procedures used at the University of California, Santa Cruz. In: Heine JN (ed) Blue water diving guidelines. California Sea Grant College, La Jolla, CA, p 28-42

Costello JH, Klos E, Ford MD (1998) In situ time budgets of the scyphomedusae Aurelia aurita, Cyanea sp., and Chrysaora quinquecirrha. J Plankton Res 20(2):383-391

Davis CS, Gallager SM, Solow AR (1992) Microaggregations of oceanic plankton observed by towed video microscopy. Science 257:230-232

Davis CS, Gallager SM, Marra M, Stewart WK (1996) Rapid visualization of plankton abundance and taxonomic composition using the video plankton recorder. Deep-Sea Res II 43:1947-1970

Feigenbaum D, Kelly M (1984) Changes in the lower Chesapeake Bay food chain in presence of the sea nettle Chrysaora quinquecirrha (Scyphomedusa). Mar Ecol Prog Ser 19:39-47

Forward RB Jr (1988) Diel vertical migration: zooplankton photobiology and behaviour. Oceanogr Mar Biol Annu Rev 26:361-393

Frandsen KT, Risgard HU (1997) Size dependent respiration and growth of jellyfish Aurelia aurita. Sarsia 82:307-312

Gallager SM, Davis CS, Epstein AW, Solow A, Beardsley RC (1996) High-resolution observations of plankton spatial dis- tributions correlated with hydrography in the Great South Channel, Georges Bank. Deep-Sea Res II 43:1627-1663 Gibbons MJ, Stuart V, Verheye HM (1992) Trophic ecology of carnivorous zooplankton in the Benguela. S Afr J Mar Sci 12:421-437

Graham WM (1994) The physical oceanography and ecology of upwelling shadows. PhD thesis, University of California Santa Cruz

Graham WM (2001) Numerical increases and distributional shifts of Chrysaora quinquecirrha (Desor) and Aurelia aurita (Linné) (Cnidaria: Scyphozoa) in the northern Gulf of Mexico. Hydrobiologia 451:97-111

Graham WM, Pages F, Hamner WM (2001) A physical context for gelatinous zooplankton aggregations: a review. Hydrobiologia 451:199-212

Graham WM, Martin DL, Felder DL, Asper VL, Perry HM (2003) Ecological and economic implications of a tropical jellyfish invader in the Gulf of Mexico. Biol Invasions 5: 53-69

Grant S, Ward P, Murphy E, Bone D, Abbott S (2000) Field comparison of an LHPR net sampling system and an Optical Plankton Counter (OPC) in the Southern Ocean. J Plankton Res 22:619-638

Halliday NC, Coombs SH, Smith C (2001) A comparison of LHPR and OPC data from vertical distribution sampling of zooplankton in a Norwegian fjord. Sarsia 86:87-99

Hamner WM (1988) Behavior of plankton and patch formation in pelagic ecosystems. Bull Mar Sci 43(3):752-757

Hamner WM (1995) Sensory ecology of scyphomedusae. Mar Freshw Behav Physiol 26:101-118

Hamner WM, Madin LP, Alldredge AL, Gilmer RW, Hamner PP (1975) Underwater observations of gelatinous zooplankton: sampling problems, feeding biology, and behavior. Limnol Oceanogr 20(6):907-917

Hamner WM, Hamner PP, Strand SW (1994) Sun-compass migration by Aurelia aurita (Scyphozoa): population retention and reproduction in Saanich Inlet, British Columbia. Mar Biol 119:347-356

Harbison GR (1992) Observations on the swimming and buoyancy of Cymbulia peroni (Gastropoda: Thecosomata) made from a submersible. J Mar Biol Assoc UK 72:435-446

Harbison GR, Matsumoto GI, Robison BH (2001) Lampocteis cruentiventer gen. nov., sp. nov.: a new mesopelagic lobate ctenophore, representing the type of a new family (class Tentaculata, order Lobata, family Lampoctenidae, fam. nov.). Bull Mar Sci 68:299-311

Hardy AC (1926) A new method of plankton research. Nature 118:630

Herman AW (1988) Simultaneous measurement of zooplankton and light attenuance with a new optical plankton counter. Cont Shelf Res 8:205-221

Herman AW (1992) Design and calibration of a new optical plankton counter capable of sizing small zooplankton. Deep-Sea Res 39:395-415

Kasuya T, Ishimaru T, Murano M (2001) In situ measurement of the lobate ctenophore Bolinopsis mikado (Moser) abundance by the video recording system. J Oceanogr 57:115-118

Laval P, Braconnot JC, Carré C, Goy J, Morand P, Mills CE (1989) Small-scale distribution of macroplankton and micronekton in the Ligurian Sea (Mediterranean Sea) as observed from the manned submersible Cyana. J Plankton Res 11(4):665-685

Lee DS, Hall DJ (1989) Quantitative sampling of organisms/ macroparticulates with a ROV using a collimated illumination system. In: Mar Technol Soc Annu Conf Proc. Oceans 89: the global ocean, Vol 3. Marine Technology Society, Washington, DC, p 827-831 
Lenz J, Schnack D, Petersen D, Kreikemeier J, Hermann B, Mees S, Wieland K (1995) The Ichthyoplankton Recorder: a video recording system for in sity studies of small-scale plankton distribution patterns. ICES J Mar Sci 52:409-417

Mackie GO, Mills CE (1983) Use of the Pisces IV submersible for zooplankton studies in coastal waters of British Columbia. Can J Fish Aquat Sci 40:763-776

Madin LP (1988) Feeding behavior of tentaculate predators: in situ observations and a conceptual model. Bull Mar Sci 43:413-429

Mills CE, Pugh PR, Harbison GR, Haddock SHD (1996) Medusae, siphonophores and ctenophores of the Alboran Sea, south western Mediterranean. Sci Mar 60:145-163

Monger BC, Chinniah-Chandy S, Meir E, Billings S, Greene $\mathrm{CH}$, Wiebe PH (1998) Sound scattering by the gelatinous zooplankters Aequorea victoria and Pleurobrachia bachei. Deep-Sea Res 45(7):1255-1271

Olesen NJ (1995) Clearance potential of jellyfish Aurelia aurita, and predation impact on zooplankton in a shallow cove. Mar Ecol Prog Ser 124:63-72

Olesen NJ, Frandsen K, Riisgård HU (1994) Population dynamics, growth and energetics of jellyfish Aurelia aurita in a shallow fjord. Mar Ecol Prog Ser 105:9-18

Olney JE, Houde ED (1993) Evaluation of an in situ silhouette photography in investigations of estuarine zooplankton and icthyoplankton. Bull Mar Sci 52:845-872

Omori M, Hamner WM (1982) Patchy distribution of zooplankton: behavior, population assessment and sampling problems. Mar Biol 72:193-200

Ortner PB, Cummings SR, Aftring RP, Edgerton HE (1979) Silhouette photography of oceanic zooplankton. Nature 277:50-51

Ortner PB, Hill LC, Edgerton HE (1981) In situ silhouette photography of Gulf Stream zooplankton. Deep-Sea Res II 28:1569-1576

Orzech JK (1984) The use of deep-diving systems in marine research. Oceans 2:1005-1009

Pages F, White MG, Rodhouse PG (1996) Abundance of gelatinous carnivores in the nekton community of the Antarctic Polar Frontal Zone in summer 1994. Mar Ecol Prog Ser 141:139-147

Pogodin AG (1998) Aurelia limbata - a new component of the scyphomedusan fauna of the Sea of Japan. Russ J Mar Biol 24(4):264-265

Postel L, Fock H, Hagen W (2000) Biomass and abundance. In: Harris RP, Wiebe PH, Lenz J, Skjoldal HR, Huntley M (eds) Zooplankton methodology manual. Academic Press, San Diego, p 83-192

Purcell JE (1992) Effects of predation by the scyphomedusan Chrysaora quinquecirrha on zooplankton populations in Chesapeake Bay, USA. Mar Ecol Prog Ser 87:65-76

Purcell JE (1997) Pelagic cnidarians and ctenophores as predators: selective predation, feeding rates, and effects on prey populations. Annu Inst Oceanogr 73(2):125-137

Purcell JE, Brown ED, Stokesbury KDE, Haldorson LH, Shirley TC (2000) Aggregations of the jellyfish Aurelia labiata: abundance, distribution, association with age-0 walleye pollock, and behaviors promoting aggregation in Prince William Sound, Alaska, USA. Mar Ecol Prog Ser 195:145-158

Raskoff KA (2001) The impact of El Niño events on populations of mesopelagic hydromedusae. Hydrobiologia 451: $121-129$

Sameoto D, Cochrane N, Herman A (1993) Convergence of acoustic, optical, and net-catch estimates of euphausiid abundance: use of artificial light to reduce net avoidance. Can J Fish Aquat Sci 50:334-346

Editorial responsibility: Jennifer Purcell (Contributing Editor), Anacortes, Washington, USA
Sameoto D, Wiebe P, Runge J, Postel L, Dunn J, Miller C, Coombs S (2000) Collecting zooplankton. In: Harris RP, Wiebe PH, Lenz J, Skjoldal HR, Huntley M (eds) Zooplankton methodology manual. Academic Press, San Diego, p 55-81

Schulze PC, Strickler JR, Bergstrom BI, Berman MS and 11 others (1992) Video systems for in situ studies of zooplankton. Arch Hydrobiol Beih Ergeb Limnol 36:1-21

Schulze PC, Williamson CE, Hargreaves BR (1995) Evaluation of a remotely operated vehicle (ROV) as a tool for studying the distribution and abundance of zooplankton. J Plankton Res 17:1233-1243

Schuyler Q, Sullivan BK (1997) Light responses and diel migration of the scyphomedusa Chrysaora quinquecirrha in mesocosms. J Plankton Res 19(10):1417-1428

Silguero JMB, Robison BH (2000) Seasonal abundance and vertical distribution of mesopelagic calycophoran siphonophores in Monterey Bay, CA. J Plankton Res 22:1139-1153

Skjoldal HR, Wiebe PH, Foote KG (2000) Sampling and experimental design. In: Harris RP, Wiebe PH, Lenz J, Skjoldal HR, Huntley M (eds) Zooplankton methodology manual. Academic Press, San Diego, p 33-53

Smith SL, Pieper RE, Moore MV, Rudstam LG, Greene CH, Zamon JE, Flagg CN, Williamson CE (1992) Acoustic techniques for the in situ observation of zooplankton. Arch Hydrobiol Beih Ergeb Limnol 36:23-43

Sprules WG, Bergstrom B, Cyr H, Hargreaves BR and 5 others (1992) Non-video optical instruments for studying zooplankton distribution and abundance. Arch Hydrobiol Beih Ergeb Limnol 36:45-58

Steinberg DK, Silver MW, Pilskaln CH, Coale SL, Paduan JB (1994) Midwater zooplankton communities on pelagic detritus (giant larvacean houses) in Monterey Bay, California. Liminol Oceanogr 39:1606-1620

Tiselius P (1998) An in situ video camera for plankton studies: design and preliminary observations. Mar Ecol Prog Ser 164:293-299

Trégouboff G (1956) Prospection biologique sous-marine dans la région de Villefranche-sur-Mer en juin 1956. Bull Inst Oceanogr (Monaco) 1085:1-24

Warner AJ, Hays GC (1994) Sampling by the Continuous Plankton Recorder survey. Prog Oceanogr 34:237-256

Warren JD, Stanton TK, Benfield MC, Wiebe PH, Chu D, Sutor M (2001) In situ measurements of acoustic target strengths of gas-bearing siphonophores. ICES J Mar Sci 58:740-749

Watanabe T, Ishii H (2001) In situ estimation of ephyrae liberated from polyps of Aurelia aurita using settling plates in Tokyo Bay, Japan. Hydrobiologia 451:247-258

Wright DA, Purcell JE (1997) Effect of salinity on ionic shifts in mesohaline scyphomedusae, Chrysaora quinquecirrha. Biol Bull 192:332-339

Youngbluth MJ (1985) Investigations of soft-bodied zooplankton and marine snow using research submersibles. Int Symp Mar Plankton 37(2):782-783

Youngbluth MJ, Båmstedt U (2001) Distribution, abundance, behavior and metabolism of Periphylla periphylla, a mesopelagic coronate medusa in a Norwegian fjord. Hydrobiologia 451:321-333

Youngbluth MJ, Kremer P, Bailey TG, Jacoby CA (1988) Chemical composition, metabolic rates and feeding behavior of the midwater ctenophore Bathocyroe fosteri. Mar Biol 98:87-94

Zhang X, Roman M, Sanford A, Adolf H, Lascara C, Burgett R (2000) Can an optical plankton counter produce reasonable estimates of zooplankton abundance and biovolume in water with high detritus? J Plankton Res 22:137-150

Submitted: April 16, 2002; Accepted: January 17, 2003

Proofs received from author(s): May 2, 2003 